\title{
La kulturkampf del neoconservadurismo americano. La recreación del consenso social en las economías capitalistas desarrolladas desde la relectura de la tradición liberal
neo-conservadora
}

José María Mardones

El denominado neoconservadurismo (NC) norteamericano es un fenómeno sociopolítico y cultural protagonizado por un grupo de prestigiosos analistas sociales. Senala una "tendencia" más que un "movimiento".' Su interés estriba en el alcance de sus pretensiones: con ello nos sumergimos en un diagnóstico de nuestro tiempo, sobre todo de la denominada crisis de las sociedades burguesas del capitalismo, y en un enérgico intento de recrear un nuevo consenso sociopolítico en la sociedad norteamericana. Hay, por tanto, un proyecto de legitimación de un modo de concebir la interrelación entre la economia, la política y la cultura que denominarán capitalismo democrático. ${ }^{2}$ Pero los perfiles concretos sólo se delimitan claramente, entre los potenciales seguidores del sistema, cuando se atiende a los rasgos que resaltan o critican. De ahl que la demarcación frente a sus adversarios sea muy importante. De hecho, este esfuerzo recreador de un nuevo consenso lo ven minado por una corriente opuesta que actúa en la sociedad americana: "la cultura adversaria" (L. Trilling) de "la nueva clase" intelectual. No tiene nada de extrano que los neoconsenadores definan su tarea en este contexto de enfrentamiento como una kulturkampf (p. Berger; Ch. Lash). 
Atender a esta "lucha cultural" significa prestar atención a uno de los intentos más sofisticados ${ }^{3}$ y quizá de repercusión sociopolítica y cultural real, más importantes y, consiguientemente, en el mundo occidental.

En esta exposición me voy a centrar en los elementos fundamentales de esta controversia, que pasa por la reconstrucción de la tradición liberal que persiguen el NC (apartado II). Será reconstrucción o tipo ideal, ya que es fruto de la conjunción de varias propuestas que se deben a autores diferentes y que hasta hoy permanecen separados. Para contextualizar este proyecto que se desarrolla en forma de lucha cultural tendremos en cuenta los diversos factores que explican esta confrontación (apartado I). Indicaremos el objetivo de esta guerra cultural: crear una nueva ética pública que proporcione un nuevo consenso en la sociedad norteamericana (apartado III).

\section{El proceso de una ruptura}

La sociedad americana está culturalmente dividida. Esta es la conclusión que se obtiene oyendo las valoraciones de los $\mathrm{NC}^{4}$ y los no neoconservadores ${ }^{5}$ sobre las actitudes y valores en la sociedad americana. El comienzo de las presentes hostilidades hay que situarlo en los anos sesenta, cuando se forjan conceptos como los de "contracultura", Middle America o "la mayoría silenciosa", pero sus origenes son mucho más lejanos.

De una forma un tanto grosera y simplista se puede hablar de una Cultural civil war entre "tradicionalistas" y "modernizadores" (T. Gitlin), entre aliberales de izquierda y conservadores" (Wuthnow, Steinfels). Intentando precisar mucho más, "entre la clase media tradicional encabezada hoy por los hombres de negocios contra la nueva clase del conocimiento" ( $p$. Berger), o entre los diversos aspirantes a la herencia civico-religiosa protestante (Neuhaus).

Pero, más allá de los protagonistas, ¿cómo se ha llegado a esta división en dos campos contrapuestos?

\section{En el princlplo la amblguedad}

El puritanismo ha dejado su marca indeleble en la sociedad americana. La roca de Plymouth es un simbolo de la persistencia de lo que Weber llamó la tendencia "ascética intramundana". La valoración del dominio del mundo, empujada por una actitud de veneración al Creador y de desconocimiento de sus designios, va forjando psicologias emprendedoras, disciplinadas, y austeras. 
Pero cuando nos situamos a la altura del siglo XIX y la industrialización es visible en América. Tocqueville ya advierte una ambigüedad en el seno mismo de la sociedad americana: el publlic commitment con la justicia y el bienestar común tiene que coexistir con las fuertes tendencias hacia el interés privado que desata la industrialización económica. ${ }^{50}$ Aqui yace una amenaza que a juicio de algunos analistas sociales se ha cumplido: ha concluido con el predominio unilateral de las tendencias individualisas en contra de las comunitarias. El individualismo liberal se ha elevado denominador sobre el comunitarismo republicano (W. Sullivan, R. Bellah). Más aún ha conseguido presentarse como la tradición genuinamente norteamericana e incluso a supeditar a ella el desarrollo legal posterior. ${ }^{5 b}$

Algunos intérpretes ven las raices de estas tendencias en los federalistas (1787) que acentúan una interpretación de la Constitución como garantía de la seguridad individual en vez de enfatizar la responsabilidad por el destino de la comunidad política, típica de la tradición biblica-republicana y los padres fundadores.

El siglo $X I X$, sobre todo tras la guerra civil, senalará el predominio creciente de la concepción liberal centrada en el negocio del interés individual. La compatibilidad de una ética de la acumulación del capital y el crecimiento económico mediante la iniciativa privada, el ahorro, y la producción, parece clara. Se forja asi la imagen de una ética puritana individualista propia de un capitalismo precorporativo y de un estilo de vida semirnal y de pequena ciudad ( $A$. Vidich/Bensens, Bell), que ha ocupado la escena de vida norteamericana hasta la segunda década del siglo XX.

Este puritanismo va a sufrir un primer ataque serio por parte de los "jóvenes intelectuales" (W. Lippmann, Van Wyck Brooks, J. Reed, H. Steams), que hacia 1915 declaran "la mayoria de edad de América". Es decir, la necesidad de una cultura que reflejaria la mayor complejidad de la vida norteamericana y los cambios acontecidos en ella. Pero su llamada a una ética del hedonismo, del placer y del juego se va a asentar no tanto por ello cuanto por los desplazamientos que van a ocurrir dentro del mismo capitalismo.

Nos encontramos asl con un proceso de erosión en dos niveles (D. Bell) sufrido por los valores tradicionales americanos: en "el reino de la cultura y las ideas" y en el de "la estructura social misma".

\section{La herencla puritana se cuartea}

Ha sido D. Bell entre los NC quien ha apuntado claramente al ca- 
rácter autodestructivo que ha tenido la evolución del capitalismo sobre el orden cultural y de los valores." Concretamente, el paso capitalismo liberal y del laisser-faire al capitalismo de consumo de masas que acontece en los anos veinte tiene los efectos de un cataclismo sobre los valores predominantes del calvinismo puritano. ${ }^{7}$

"La ética protestante fue socavada no por el modemismo, sino por el propio capitalismo. El más poderoso mecanismo que destruyó la ética protestante fue elpago en cuotas o en crédito inmediato. Antes era menester ahorrar para poder comprar. Pero con las tarjetas de crédito se hizo posible lograr gratificaciones inmediatas. El sistema se trasformó por la producción y el consumo masivos por la creación de nuevas necesidades y nuevos medios de satisfacerlas". ${ }^{8}$

El "nuevo capitalismo" generó una "ética del consumo". Minó el núcleo central de ética puritana, el ahorro, la abstenencia o frugalidad y lo sustituyó por "la moralidad de la diversión". "Vender se convirtió en la más descollante actividad de la Norteamérica contemporánea. Contra la fngalidad, la venta exaltaba la prodigalidad; contra el ascetismo, la pompa dispendiosa"."

Las consecuencias de este giro- no se hacen esperar: "Cuando la ética protestante fue apartada de la sociedad burguesa, sólo quedó el hedonismo y el sistema capitalista perdió su ética transcendental". ${ }^{10} \mathrm{Se}$ Introduce asl un modelo cultural, centrado en el placer como modo de vida, que choca frontalmente con la lógica exigida por el orden económico. "Aqul reside la contradicción cultural del capitalismo"."

Este proceso de cambio moral impulsado por el capitalismo del consumo masivo se va a consolidar con la crisis del 29 y su superación a través del keynesianismo roosveltiano del New Deal. Aparace claro que la forma de estimular la economla es a través de la demanda y no de la producción. Es necesario estimular el consumo, y crear las condiciones sociales para ello. El intervencionismo estatal, el pacto socioeconomico entre trabajadores y empresarios que convierte a los trabajadores en crecientes consumidores, la publicidad y la extensión del crédito serán algunas de las medidas que marcan el paso al modemo capitalismo de intervención estatal. Con ello se dice adiós a la vieja moral calvinista del ahorro y la gratificación propuesta en favor de la nueva ética del consumo y de la gratificación inmediata. ${ }^{12}$

Tras la Segunda Guerra Mundial, con las expectativas crecientes de un keynesianismo redentor de las situaciones de pobreza (Welfare State) se generalizan los valores del consumismo y de to que Bell y los NC denominarán el hedonismo como forma de vida. 
Pero serla demasiado precipitado afirmar la desaparición de los valores que acompanaban a la vieja clase media americana y a los hombres de empresa. La crisis del Estado de Bienestar, visible ya con el presidente $L$. Johnson y acelerada por la guerra del Vietnam, y la crisis energética van a suponer el cuestionamiento no sólo del keynesianismo como política económica, sino de los valores inducidos y promovidos por "la ética del consumo" y "la moralidad de la diversión".

Este punto, sin embargo, merece un poco más de atención dado que es el que justifica la reacción NC y juicios como el de Richard J. Neuhaus acerca de "la plaza pública norteamericana desnuda"13 y necesitada, por tanto de ser poblada o de recrear un "hogar público" (D. Bell).

\section{La consolldaclón de la dlvisión}

Cuando nos preguntamos por los elementos que han favorecido el distanciamiento respecto a la ética puritana, nos encontramos con una serie de factores sociales senalados por los analistas: ${ }^{14}$ el gran incremento de la productividad tras la Segunda Guerra Mundial; la consiguiente burocratización de la empresa y la vida sociopolítica, la emergencia de una nueva clase más educada y ocupada en el área de los servicios; el creciente intervencionismo estatal para sostener la solución keynesiana.

La conjunción de esos factores, con el entramado de elementos que presuponen, va a favorecer una serie de cambios en el ámbito motivacional y de los valores. Con el lenguaje de Bell hablariamos de un giro en el significado del trabajo y la acumulación: "ya no eran fines en si mismo, sino medios, para el consumo y la ostentación $n^{m} ;{ }^{15}$ el establecimiento de la idea del cambio y el crecimiento continuos junto con la cultura modemista socavarán los valores burgueses y las pautas tradicionales de la vida norteamericana. ${ }^{16}$

Dentro del conjunto de elementos que consolida la división cultural en la sociedad estadounidense hay uno que merece ser destacado por la relevancia que adquiere en el NC. Se trata de la emergencia a través del gran crecimiento económico de una nueva clase media y de la expansión de sus valores a través de la educación.

Una de las consecuencias sacadas por Estados Unidos de su intervención en la Segunda Guerra Mundial fue la gran importancia de la ciencia y la tecnologla para la defensa. EI Proyecto Manhattan supuso un empuje a la edución y la investigación. La expansión económica favorecla la realización de este programa. $Y$ el boom demográfico de la población hacla pasar el número de estudiantes de 16,2 millones en 
1960 a 24,4 en 1970. Los efectos no se dejaron esperar: desde 1946 a 1975 uno de cada dos premios Nobel en ciencia procede de Estados Unidos y la Administración crecerá hasta terner un 35 por 100 de profesionales y trabajadores técnicos.

En el ámbito cultural los cambios de valores y actitudes serán notorios y dramáticos. ${ }^{17}$ Como sehala Wuthnow (y acusa fuertemente la sensibilidad NC), será en el área del igualitarismo donde más claramente se perciben: ${ }^{10}$ crece la tolerancia ideológica respecto a judios y católicos; la racial, respecto a los negros y frente a grupos considerados marginados (comunistas, ateos y homosexuales), y se liberalizan las actitudes respecto al divorcio, las relaciones prematrimoniales y las orientaciones económicas.

A la altura de los años setenta y tras la experiencia de la contracultura, los movimientos de derehos civiles, la nueva izquierda de los anos sesenta y la liberación femenina, comenzará a aparecer la interpretación NC de una "nueva clase". Es fruto del auge de esas clases medias y de la expansión de educación secularizada. Será la portadora de "las fuerzas modernistas que llevarán la lucha contra las tradicionalistas en los problemas sociales y culturales". "A juicio de Bell esta "nueva clase" es "una mezcla de intelectuales, profesores e individuos partidarios del bienestar y de mente reformista, unidos por razones políticas, por obra de dirigentes sindicales y políticos de grupos étnicos, que representaban a las fuerzas urbanas".20

El shock producido por la guerra del Vietnam y la humillación americana final, y la aparición de la clausura de "la gran prosperidad (195070)" van a marcar el surgimiento de una sensibilidad nostálgica respecto a los viejos valores de la ética puritana. Es una reacción que hunde sus raices en el fracaso del keynesianismo moral creciente y la denominada contracultura.

Saltan al espacio público, con visibilidad y peso social creciente, grupos y tendencias más conservadoras. Grupos religiosos en la derecha (New Right) reaccionan contra to que denominan un humanismo secular y comienza a jugar un rol importante en la movilización política. La "Mayoria Moral" será una manifestación de ello.

Otros grupos propondrán una regeneración moral de la sociedad americana y un retorno a la producción de valores. Los viejos conservadores, lo denominados neoliberales y los NC se encuentran en esta propuesta. Pero sus programas divergen y, como veremos, hay notables diferencias entre ellos.

Pero para nuestro propósito en este momento basta indicar que a la 
altura de los anos setenta y ochenta se han polarizado las tendencias en la sociedad norteamericana. La guerra cultural desatada esta vez por las tendencias conservadoras está en su apogeo. Ahora bien, ¿qué está en juego en esta lucha para que le prestemos atención más allá de una escaramuza sociocultural de la sociedad norteamericana?

\section{La crisls de la cultura burguesa llberal}

La respuesta a la cuestión anterior desde el pensamiento NC nos introduce en el núcleo del problema que afrontan. Una breve exposición de las formulaciones que adopta esta respuesta en los diversos autores nos proporciona, a la vez que un pequeno panorama de resonancias y matrices, un esquema interpretador o de diagnóstico de la enfermedad que aqueja a la sociedad norteamericana y concretamente a su filosofia pública liberal. Veamos algunas de las respuestas.

a) Las contradicciones socioculturales del capitalismo no son sólo del capitalismo, sino de la sociedad burguesa. Esta sería la tesisdiagnóstica de $D$. Bell. ${ }^{21}$ Este autor ve, en una visión histórica retrospectiva, que la sociedad burguesa está atravesada por una tendencia a la autorrealización y al autointerés que desata dos desarrollos contradictorios: en lo económico da origen al empresario burgués, cuyo ideal fue el libre movimiento de los bienes y del dinero, la movilidad economica y social del individuo; en la cultura propicia la aparición del artista independiente, no sólo de los patronos, sino de todas las convenciones. Son dos aspectos de un mismo proceso. En sus formas extremas dieron origen al laisser-faire y aun desenfrenado individualismo. Dos mundos que entran pronto en contradicción. El puritanismo norteamericano trata de frenar esta oposición controlando los excesos del individualismo cultural, pero dejando crecer el individualismo radical en economia. La cólera de Baudelaire contra el utilitarismo productivo americano presagiaba ya la disyunción que Bell ve aparecer claramente cuando la cultura modernista rompa los controles puritanos. Desembocará en "la idolatría del yo".2z

La contradicción que supone esta lógica de la autorrealización y expresión cultural respecto a la racionalidad instrumental de la producción económica y la búsqueda del bien común sociopolítico será considerada por Bell la contradicción fundamental no sólo del capitalismo, sino de la sociedad burguesa. Controlar y enderezar el orden cultural se convertirá en el problema central de la crisis actual. Solucionar la incompatibilidad de valores que vivimos en nuestra sociedad (libertad e igualdad, eficiencia y espontaneidad, conocimiento y felicidad) mediante la elección será la necesidad imperiosa ante la que nos 
encontraremos. Un problema con connotaciones económicas, políticas y culturales que exigen a juicio de Bell, una nueva filosofia pública u "hogar público",23 que será, en último término, una reinterpretación de la tradición liberal.

b) El espiritu del capitalismo es democrático. Cuando se olvida que el capitalismo es un sistema económico que depende de un espiritu moral, pero que necesita del sistema político democrático para subsistir, desembocamos en el Estado patrimonial (M. Novak). ${ }^{24}$ De ahi que, a juicio de M. Novak, el problema que tienen que afrontar claramente las sociedades occidentales es el de evitar la penetración del totalitarismo. Los enemigos del sistema del capitalismo democrático son todos aquellos que propician de alguna forma modos colectivistas. Se amenaza asi la libertad para la existencia libre del mercado y de la propiedad privada, sin las cuales un sistema político no puede asegurar ni el pluralismo ni la defensa de las libertades fundamentales. ${ }^{25}$

No tiene nada de extrano que la crisis de la sociedad (occidental) la vea Novak estrechamente ligada no sólo a la cultura modernista y adversaria, sino a un debilitamiento de la tradición judeo-cristiana. Se ha perdido de vista sobre todo la afinidad entre judeo-cristianismo y sociedad democrático-capitalista. La pérdida del "vínculo trascendental" (Bell) será también para Novak la cuasa de la crisis espirituafo de nuestro tiempo y de la creciente expansión del mito socialista. ${ }^{27}$

El énfasis en la afinidad electiva entre la tradición judeo-cristiana, el sistema económico capitalista de libre mercado y el sistema político democrático representativo será leitmotiv del intento de Novak por mostrar frente a sus críticos de "la nueva clase" que todo lo que atente contra uno de los elementos de la triada es una amezanaza a la estabilidad de la sociedad.

c) La sociedad americana carece de filosofia pública. La ha perdido y vive en una plaza pública vacia (Richard J. Neuhaus). No ha perdido los valores operativos ni la piedad pública, ha descuidado la tarea cognitiva e intelectual de dar sentido a la democracia liberal y concretamente a la sociedad democrática liberal americana.

Una tarea en la que Neuhaus ${ }^{28}$ ve necesariamente comprometidos a intelectuales e iglesias, pero que tiene que responder a las exigencias y necesidades populares. Porque la ética civica para ser democrática tiene que ser popular.

La crisis, por tanto, de la democracia liberal tiene mucho que ver con los prejuicios antidemocráticos de la nueva clase ${ }^{29}$, y con la abdicación del protestanismo americano de las tareas públicas-morales. ${ }^{30}$ Más 
concretamente Neuhaus ve más en la inadecuada militancia política evangélica y fundamentalista el origen cercano del vacio de la plaza pública que en el humanismo secularista. Para nuestro autor -como para todos los NC- la crisis de la sociedad democrático-liberal es una crisis de legitimización moral. Por esta razón esta estrechamente vinculada con los productores de teorias legitimadoras: los intelectuales $y$ la presencia pública de la religión y la fundamentacion religiosa-moral de la conducta pública en los asuntos económicos sociales y políticos. Este autor cree que la solución de la débil creencia en la legitimidad moral de la sociedad democrática-liberal está solicitando del catolicismo la sustitución de la producción de sentido y legimidad moral que anteriormente le correspondió al protestantismo."

d) El consenso social fraguado en los últimos treinta años en la sociedad norteamericana alrededor del igualitarismo se ha roto. Estamos ante el intento de construir un nuevo consenso social desde el otro gran valor del credo americano: el individualismo. Esta es la tesis del politólogo neoconservador S. Martin Lipset. ${ }^{32}$

Para este autor las contradicciones que refleja la sociedad y politica estadounidense proceden del dualismo que se asienta en el corazón del credo americano: la oposición entre individualismo e igualitarismo, fondo de las luchas entre conservadores y liberales.

Esta "compartimentalización" de la mente y las actitudes norteamericanas entre igualitarismo y realización a través del individualismo competitivo es el resultado de la ideologia nacional nacida de una estructura social sin vinculos con un pasado feudal, y fuertemente marcada por una conciencia de la responsabilidad individual introducida por la religión de las sectas disidentes protestantes. ${ }^{30}$

Precisando más el diagnóstico, Lipset dirá que las confrontaciones entre moralismo igualitarista y voluntarismo individualista - tal y como se han desarrollado en las luchas en pro de los derechos civiles, de la guerra del Vietnam, etc., en las décadas sesenta y setenta- indica claramente el fracaso de la política del socialismo e izquierda americanos y muestra sus contradicciones internas. ${ }^{34}$ para Lipset, por consiguientes, se trata, por una parte, de una contradicción secular insita en la tradición religioso-cultural y política norteamericana y, por otra, de las divisiones e incompetencias de la izquierda politica. Deja claro que hay una tarea intelectual y política: conjugar los fines comunes con los medios individuales para realizarlos. ${ }^{35}$

A través de este breve recorrido por el diagnóstico NC de la crisis queda claro el problema principal que se debate: la necesidad de una filosoffa pública que reinterprete la tradición liberal y proporcione el sen- 
tido normativo o legitimidad moral de la sociedad democrático-capitalista.

Esta tarea hay que realizarla en una sociedad norteamericana polarizada en los valores y las actitudes, con la presencia de "una cultura adversaria" a la tradición liberal sostenida por "la nueva clase" intelectual. Este clima justifica que la reconstrucción de la tradición liberal sea vista y vivida con una kutturkampf.

Ya hemos insinuado algunos de los puntos hacia los que se inclina la reinterpretación NC del liberalismo, pero vamos a detenernos más en su análisis.

\section{Hacla la reconstrucción NC de la tradición Ilberal}

Argumentamos y razonamos siempre dentro de una tradición. ${ }^{30} \mathrm{La}$ tendencia NC no oculta que se mueve dentro de la tradición democrática y liberal. Percibe, desde la situación histórica apuntada, que esta tradición está pidiendo una reconstrucción, una reinterpretación. Y será esta reinterpretación la que haga del grupo NC unos productores de legitimación que, apoyados por instituciones, fundaciones y la presencia en los puestos administrativos, ${ }^{37}$ convierta su intento en un fenómeno sociocultural y político digno de atención.

\section{A la búsqueda de las raices proplas}

Hay una preocupación en los pensadores NC por referirse claramente a sus raices inspiradoras, en este afán delimitador no sólo hay búsqueda de identidad sino un ejercicio de oposición a la "cultura adversaria".

EI NC ve una doble tradición ilustrada: la ilustración anglo-escocesa, que está en los orígenes de la sociedad americana, y la ilustración francesa o continental madre de la tracasada Revolución Francesa y del socialismo. ${ }^{38}$

Tres son los acentos principales colocados por los NC al efectuar esta confrontación de tradiciones ilustradas:

a) La superioridad de la ilustración anglo-escocesa. La ilustración sajona, dirán, ha demostrado históricamente su superioridad sobre la francesa: la prueba está en el triunfo de sus inspiraciones político-sociales. Mientras que la Revolución Francesa es una revolución fracasada, el capitalismo democrático americano que procede de sajona es "la única revolución de la modernidad concluida con éxito" (H. Arendt)..$^{30}$

La contrastación empírico-histórica demostraría, por tanto, la supo- 
rioridad de la inspiración ilustrada que está detrás de ella. $Y$ más allá hay que leer una deslegitimación de aquellos intelectuales "de izquierda", nueva clase intelectual, afines a esta ilustración francesa fracasada.

Pero ¿de dónde procede la atracción que parece despierta esta tradición ilustrada fracasada?

Al dar una respuesta a esta cuestión los NC acentuaan la diferencia de estilo de ambas tradiciones y de sus promesas.

b) Las virtudes puritanas de la ilustración anglo-escocesa. El atractivo de la ilustración francesa yace en el espejismo que provoca: la brillantez, la expositiva de sus representantes y la utilización de un estilo utópico, gnóstico que funciona como un senuelo para los espiritus disgustados que pueblan las ciencias sociales y humanas. ${ }^{40}$

Por contraposición la tradición anglo-escocesa está alejada del entusiasmo de las promesas radicales y totalizantes e impulsa una mejora gradual de la sociedad. No oculta su escepticismo frente a las pretendidas promesas de cambio total que llevan adheridas afirmaciones dogmáticas acerca del hombre y el sentido de la historia. No promete ninguna salvación dentro de la historia, por lo que la anima la calma sociohistórica carente de mesianismo. Su aportación es un meliorismo, lento pero sostenido, tanto de condiciones materiales como de la libertad individual y social. ${ }^{41}$ Crecimiento sostenido, dinamismo de innovación y libertad individual y social son los elementos típicos del capitalismo democrático que el NC ve ya como constitutivos de la promesa ilustrada anglo-sajona.

c) Los impulsores de una tradición. La sociedad y el realismo son las virtudes practicadas por los ilustrados anglo-escoceses y preferidas por el NC. De aqui que sus autores sean evocados como los intérpretes de esta tradición. Concretamente serán Adam Smith, James Madison, Thomas Jefferson (EI Federalista) y Montesquieu los considerados fundadores del "nuevo orden de la eras". ${ }^{42}$ La admiración, a decir de I. Kristol, se alarga hasta Aristóteles, el respeto a Locke y la paternidad a A. Smith, teniendo a los "padres fundadores" de la Constitución americana como a los genios políticos creadores del sistema. Más cercanos a nuestro tiempo se recuerda a Leo Strauss, R. Kirk, F. Hayek como inspiradores parciales de algunas de sus ideas. ${ }^{43}$

Tenemos así delimitada la tradición a la que se adhiere el NC. Pero de paso ya hemos percibido el carácter opositor de su autoidentificación: va acompanada de claros sintomas de minusvalidos y rechazo de aquella otra tradición que, según su interpretación, está en la raiz de "la cultura adversaria"; la identificación sirve para mostrar donde está él 
enemigo y para anatematizarlo. Una estrategia que $\mathrm{P}$. Beger (con $\mathrm{T}$. Luckmann) describió ya hace anos cuando abordó la cuestión de la confrontación de comisiones. ${ }^{\mu}$ La guerra cultural queda declarada a los herederos de una tradición crítico-ilustrada, proseguida hoy en el socialismo y que tiene sus representantes en la sociedad americana entre profesores de las ciencias sociales y humanas y "la nueva clase del conocimiento" (D. Bell).45

¿Será el NC sólo una kulturkampf entre élites intelectuales? En sus manifestaciones externas asi 10 parece. Incluso, como ha apuntado $S$. $M$. Lipset, es una guerra cultural entre dos facciones cercanas: la democracia socialista (Democratic Socialist) liderada por Michael Hamington, que acuno el término neoconservador para aplicárselo a los socialdemócratas (Social Democrats), que sería la rama conservadora del disuelto partido socialista norteamericano. Se comprende que sea Dissent, la revista democrático-socialista, la que más empecinadamente sostiene esta guerra cultural con los neoconservadores.

Pero el diagnóstico neoconservador va más allá de Hamington, Howe, Walzer y sus seguidores. Advierte una impregnación peligrosa de las ideas de la tradición ilustrada francesa, especialmente socialista, en todo ese grupo "idealista" de la "nueva clase" de cientfficos, abogados, urbanistas, trabajadores sociales, educadores, criminólogos, médicos de la salud pública (..) ${ }^{46}$ que propenden fuertemente hacia el "Estado de Bienestar", una versión suave del sistema económico fuertemente regulado que es la aspiración tradicional de la izquierda.

Accedemos asi a los aspectos políticos y económicos de la reinterpratación NC y su confrontación con la "nueva clase".

\section{La Ingobernabllldad del Estado sobrecargado}

La "nueva clase", piensan los NC, han politizado en exceso las necesidades. Los movimientos sociales pro derechos civiles de los años sesenta dieron un paso gigantesco en la sobrecarga del Estado respecto a sus tareas. El Estado ahora ya no sólo carga con la dirección de la economía, el apoyo a la ciencia y la tecnología, sino que asume la poIftica social nomativa. El Estado se compromete asl "no sólo a crear un sólido benefactor, sino también a corregir la influencia de todas las desigualdades económicas y sociales" ${ }^{47} \mathrm{El}$ resultado, como juzgan los NC, es un Estado sobrecargado que se hace ingobernable.48

La solución NC es descargar al Estado. Dicho con otras palabras, el orden político modemo absorbe demasiadas competencias de la economía y la cultura que debe abandonar. 
Esta despolitización de ámbitos que proponen los NC es vista por sus criticos como un ataque al Welfare State.40 La vuelta o devolución a la sociedad (al mercado y asociaciones privadas) de muchas de las demandas de "la revolución de las expectativas" o títulos (vivienda, poIltica ambiental, atención médica, apoyo a los ingresos...) quiere ser un correctivo a una desviación de la sociedad liberal "originalmente establecida en sus ethos, sus leyes y sus sistemas de recompensas, para promover fines individuales, pero ahora se ha convertido en una econo$\mathrm{mla}$ interdependiente que debe estipular metas colectivas. ${ }^{50}$

El correctivo NC al liberalismo polltico no quiere acabar con el Estado de Bienestar, pero le somete a severas restricciones. En esto se diferencian los NC de los neoliberales que friedmanitas y del reaganomisc.'1 la polémica sobre el Estado de Bienestar que recorre centenares de páginas de la revista Public Interest y al viejo conservadurismo que quisiera desmantelar el Estado de Bienestar y a "la nueva clase" intelectual, a la que ve interesada en "la guerra de la pobreza", porque asl hincha sus filas y obtienen subvenciones estatales que responden más a sus planes que a una verdadera educación o solución de los problemas. ${ }^{50}$ Sin embargo, "la nueva clase" del socialismo democrático ve en la estrategia NC de "dispersar las responsabilidades en el mercado" (D. Bell) y de volver a "las estructuras intermedias" (familia, iglesia, asociaciones...) (P. Berger, R. J. Neuhaus) un peligroso retroceso social de logros fundamentales penosamente arrancados al capitalismo (I. Howe).

La despolitización de ámbitos del Welfare State pertenece al intento NC de hacer gobernable la política y de reestructurar el hogar público o filosofla pública liberal. En el fondo se trata de solucionar lo que Bell llama el "dilema sociológico del hogar público" o filosofia pública liberal al afrontar los problemas normativos de la justicia distributiva: tiene que obtener un equilibrio entre los intereses públicos y los deseos privados y grupales ("vicios privados"). . $^{\text {st }}$ EI NC esgrime una serie de convicciones que quieren responder a la tradición liberal y "la necesidad de estimulo para el crecimiento económico: favorecer la igualdad de oportunidades, no la de resultados; ${ }^{55}$ mantener la meritocracia como principio, pues de lo contrario se pone en peligro el crecimiento económico y con ól las expectativas de mejora y la paz social; 50 reducir la coerción del gobiemo y el intervencionismo estatal a fin de salvaguardar la regla de la libre negociación. ${ }^{57}$

De aqul que las éticas que proponen principios distributivos, como el criterio maximin propuesto por Rawls, pero no tienen en cuenta la necesidad del crecimiento económico, juegan con principios de equidad 
para un "Estado estacionario". Pero no es seguro que la sociedad vote por el "Estado estacionario", opina Bell. ${ }^{50}$

Se percibe en esta recreación de la tradición liberal que el viejo problema de la incompatibilidad entre libertad e igualdad siempre recibe en el NC un énfasis sobre la libertad individual mirando de reojo al totalitarismo, por miedo a poner demasiado poder en las manos del Estado ${ }^{50}$; y una presión sobre la salvaguardia de las diferencias individuales que expresa un miedo al deslizamiento de la igualdad de oportunidades hacia la igualdad de resultados. ${ }^{\circ 0}$

Las propuestas NC sobre el Estado y la política se complementan con la defensa de la democracia representativa. Hay consenso en los autores NC al mirar como peligrosa, además de llena de problemas, a la "democracia participatoria".61 Al mismo tiempo, quieren evitar to que constituye para ellos la mayor amenaza social de nuestro tiempo: la burocratización generalizada. De nuevo el equilibrio entre libertad, participación y regulación estatal les parece a los NC que corre parejo con la potenciación de las estructuras intermedias.

"Por estructuras mediadoras quiero decir las instituciones que moldean la identidad de los individuos y les ayudan a relacionarse con las estructuras más vastas de una sociedad (...). Las más importantes de ellas son la familia, la religión institucionalizada y las estructuras comunitarias cooperativas, sindicatos y otras asociaciones que protegen o fomentan intereses particulares ${ }^{\text {"83 }}$

Las funciones de las estructuras intermedias en la sociedad altamente burocratizada es crucial: a) son la matriz de la democracia; b) evitan que los individuos caigan en la anomia o enajenación; c) garantizan los vínculos del gobierno con los valores por los cuales vive la gente ordinaria. Se ve, por tanto, que son capitales para "la legitimidad de todas las grandes estructuras políticas y especialmente del gobierno". ${ }^{\circ}$

\section{Exaltación del capltallsmo sobrlo y prosalco}

La reconstrucción NC de la tradición liberal defiende al capitalismo como el sistema u orden económico más adecuada para la sociedad democrática que proponen. De una u otra manera los autores NC afirman con P. Berger que "el capitalismo es una condición necesaria, aunque no sea suficiente, para la democracia en las condiciones modernas actuales". ${ }^{64}$

Pero cuando pretendemos obtener una definición precisa de lo que entienden por capitalismo nos encontramos con que en algunos autores 
se elude (D. Bell) ${ }^{95}$, y en aquellos que han abordado la cuestión se nos habla de "una teoría económico-cultural del capitalismo" (P. Berger) $)^{68}$ o de toda una recreación del "espíritu del capitalismo democrático" (M. Novak). ${ }^{67}$

Este tratamiento ya indica cómo para el NC es difícil hablar del capitalismo si no es viéndolo en su relación con el sistema político y cultural. Este enfoque, avalado por autores como A. Smith, M. Weber, Schumpeter y el mismo K. Marx. ${ }^{\theta \theta}$ sirve para comprender la profunda imbricación que tiene el capitalismo con la sociedad liberal que avistan los NC.

Con todo, hay una serie de acentos que han quedado subrayados en su demarcación y lucha frente a neoliberales y socialistas democráticos.

Frente a los neoliberales -aunque concuerdan con ellos en que el capitalismo es "una economia orientada a la producción mediante el intercambio en el mercado"69_, difieren en la creencia de la posibilidad y ventajas de la utopia del laisser-faire. Aceptan la realidad del intervencionismo estatal e incluso ven sus aportaciones. Por esta razón, aunque -contra las tendencias socialistas y de la "nueva clase"- temen "los crecientes grados de control estatal en la economia capitalista" ${ }^{m 70}$, sin embargo no las rechazan como algo negativo.

Una diferencia de grado es, por consiguiente, la razón por la que se apartan del socialismo democrático, llevados del miedo, dicen que de perder "el gobierno democrático de la sociedad"." La misma distancia quisieran mantener en la cuestión - ya aludida- del Welfare State.

Algunos NC ven con preocupación la evolución actual del capitalismo hacia un "capitalismo corporativo". Las corporaciones multinacionales han introducido unos cambios fundamentales en el sistema: han internacionalizado el mercado de capitales y trabajo. Ahora es difícil la economia de un pais (aunque sea Estados Unidos), pues, como observa Bell, "los planes de las corporaciones multinacionales no siempre coinciden con los intereses económicos de un pais determinado". ${ }^{71} \mathrm{~Pa}$ ra Bell, con el nacimiento de esta economia mundial que, junto con otros factores, supone una sociedad mundial, "hacen que sean de fundamental importancia los problemas de la administración de recursos", medio ambiente (océanos, clima, energia) y la construcción de nuevas formas de autoridad, regulación e integración de la economia internacional proporcionadas a la escala de todo el mundo. ${ }^{73}$ Sobre todo, urge a su juicio crear algunos sistemas monetarios nuevos que constituyan la columna vertebral de la nueva economia internacional. 
En Berger y sobre todo en Novak, aunque no se niega la ambigüedad de las corporaciones multinacionales, predomina una actitud de defensa. Se trata de mostrar las aportaciones que conllevan, siempre recelosos del excesivo intervencionismo estatal. ${ }^{74}$

La visión positiva del capitalismo que recorre el pensamiento NC se hace canto de entusiasmo y loa al elemento creativo que le dinamiza en $M$. Novak. Para este autor la raiz del "espiritu del capitalismo" hay que buscarla en ese potencial creativo que dispara e impulsa una serie de "circunstancias" propicias para su desarrollo. Novak hará hincapié en que los elementos jerárquicos-sociales y religiosos (relación IglesiaEstado) o obstaculicen el afán empresarial privado.75 De esta perspectiva -que olvida el carácter irracional y destructivo que tiene ese potencial creativo del capitalismo en Schumpeter - verán al capitalismo como el sistema más apto para el despliegue de las capacidades personales para el "crecimiento sostenido" (Weber) y la movilidad social. Combinado con la democracia política ofrecen "el sistema más abierto de estratificación social". ${ }^{76}$

Incluso Berger, después de un estudio que quiere tener el carácter desapasionado y riguroso de las hipótesis falsables, afirmará que el capitalismo no sólo es el sistema más propicio para la producción, sino también para la distribución de los bienes, tanto en el Primer como en el Tercer Mundo." Por supuesto -y éste es el obligado referente del los NC - mucho más que el socialismo.

La concepción (recreación) del capitalismo en el pensamiento NC posee un énfasis cultural-valorativo que ellos pretenden recoger de la mejor tradición capitalis ta: la de A. Smith. ${ }^{78}$

El sistema económico no subsiste sin unos valores o presupuestos éticos y antropológicos que se toman como base o garantia. Kristol nos dirá que a estos presupuestos pertenece: 1) la visión o ethos de un individualismo que "busa su mejora"; 2) la confianza en el irradicable fondo moral de la naturaleza humana; 3 ) la coherencia del sector privado bajo la influencia de la religión, los valores morales tradicionales y la familia.

En el fondo, se recoge una idea que de una $u$ otra manera resuena en nuestros autores: "ciertos componentes de la cultura burguesa occidental especialmente el activismo, la innovación racional y la autodisciplina son prerrequisitos para el éxito del desarrollo capitalismo en cualquier parte".78 D. Bell verá esta conjunción valorativo-económica y política afirmando que "si existe un consenso amplio en las sociedades occidentales, éste radica en la idea de que la opción individual y local 
en todas las cuestiones posibles es un valor deseable. Es la base de la reacción a la planificación centralizada o dirigida de los paises socialistas y la reacción a los rígidos programas y burocracias del Estado de previsión social en los países democráticos" ${ }^{n 0}$

A pesar de tantas razones para enaltecer al sistema y confiar en él, sin embargo, hay un dato cultural que impulsa a los neoconservadores en su tarea: el capitalismo carece de atractivo utópico, mítico. La capacidad mitopoética está en manos del socialismo. Este es el secreto del prestigio ideológico de uno y del vituperio del otro. Además hay que anadir a esta incapacidad mítica del capitalismo que los recreadores ideológicos le han vuelto la espalda. Hoy "la nueva clase del conocimiento es el mayor enemigo del capitalismo en las sociedades occidentales"."1 De ahl que la recreación de la tradición liberal en el NC adopte la forma de defensa ideológica del capitalismo sobrio y prosaico y de lucha cultural contra la mítica ilusoria del socialismo, aun democrático.

\section{Poner IImltes al modernlsmo hedonista}

El capitalismo democrático no es un sistema social neutro. A Smith ya 10 vio y los NC lo repiten hoy incansablemente. Pero en sus referencias concretas se advierte un diagnóstico y la orientación para la reconstucción de los valores y la cultura que deben predominar en la plaza pública liberal.

El diagnóstico de D. Bell acerca de la contradicción fundamental del capitalismo burgués es compartida por la tendencia NC. La economia moderna y el modernismo de las vanguardias hunden sus raices en un común "rechazo del pasado, un gran dinamismo, la búsqueda de la novedad y la sanción del cambio". ${ }^{22}$ Pero los diversos valores y racionalidades que recorren a la economia y la cultura los hacen en su conflicto irreconciliable. La búsqueda irrefrenable de realización del yo, que atraviesa la cultura burguesa, elevará el principio de la experimentación a los attares de la estética moderna. Desde aqui se comprende "la hybris moderna de la negatividad a aceptar límites", "la insistencia en ir continuamente más allá de sí mismo"83 y el hedonismo como justificación estética de la vida. Se produce de esta manera "la negación de los valores burgueses en la esfera del arte". Bell rechaza asi de plano el diagnóstico de los teóricos críticos (ctr. J. Habermas) de que "la mentalidad tecnocrática domina el orden cultural". Esta visión "ignora todos los elementos de juicio a mano. Lo que existe hoy es una radical disyunción de la cultura y la estructura social".es

Hemos entrado en el núcleo de diagnóstico NC acerca de la cultura moderna. La crisis cultural de nuestro tiempo radica en esa compulsiva 
búsqueda de si que no tiene fin y se ha hecho experimento ilimitado, libertad sin trabas, sensibilidad sin restricciones, imaginación inmune a la critica racional. El peligro yace en que lo logrado ya en la esfera autónoma del arte y la cultura se está trasvasando ahora al terreno de la vida.

¿Cómo parar este movimiento que choca frontalmente con el orden económico y político del capitalismo democrático? ¿Cómo imaginar (y producir) una esfera cultural y artística que responda no al principio axial del yo, sino a las normas comunes de una vida comunitaria? ¿Como poner coto a la insaciabilidad del individualismo experimental del modernismo cultural? ¿Cómo rehacer un lazo social de sentido para recrear "el hogar público" que equilibre libertad e igualdad, equidad y eficacia?

La respuesta NC apunta a una solución que ellos mismo no temen en etiquetar de conservadora. ${ }^{85}$ Caracteristico de tal postura conservadora, como solución a los problemas de la disyunción entre cultura y estructura social, son los siguientes cuatro rasgos.

En primer lugar, un fuerte énfasis en la recuperación de la tradición religiosa judeo-cristiana o de "alguna concepción de la religión" (D. Bell). Frente a "aquellas experiencias que nos dan un sentido trágico de la vida" -inevitable para el hombre que como individuo y ser social vive al filo de la navaja entre la finitud y la libertad- se necesita la religión. Para restaurar "la continuidad de las generaciones, volviéndonos a las circunstancias existenciales que son el fundamento de la humildad y el interés por los otros", se necesita la religión;"* para "imponer normas morales a la cultura" y senalar limites a los impulsos se requiere la religión, ${ }^{97}$ como también para senalar tales límites a la economia y la tecnologia. ${ }^{\oplus \theta}$ La religión aparece asl en el pensamiento NC como un constitutivo de la cultura, cuya función de donador fundamental de sentido no ha podido ser sustituido todavia con éxito. De aqui que el problema real de la modernidad sea el de la creencia y la crisis de nuestro tiempo sea una crisis espiritual".

Ligado estrechamente con la recuperación de la religión está el segundo acento NC en lo cultural: la necesidad de recuperar una ética clvica que posibilite al hombre moderno vivir en una sociedad posindustrial y democrática. Todas las indicaciones apuntan a desarrollar el sentido comunitario que exige la civitas y "obstaculizar aquellas tendencias que sovacan a su voluntad civica". Problema complejo donde se dan cita las motivaciones de los individuos, la conciencia colectiva y la adecuación de las instituciones. Una insistencia aparece en los diversos autores: la necesidad de recuperar la ética puritana cuestionada por el 
modernismo y el mismo desarrollo capitalista. Los NC apuntan críticonegativamente a este proceso de reconstrucción pública de una ética civica basada en los valores de una ética de la producción/consumo, de un individualismo contenido y de un cierto ascetismo que contenga las tendencias hedonistas. Cuando indagamos el modo de conseguirlo volvernos a encontrar la función limitadora de la religión a la vez que su apertura a los otros y sus necesidades. Bajando más a la realidad social apuntran (P. Berger/R. J. Neuhaus) a las estructuras intermedias de la escuelá, la Iglesia y la familia como elementos fundamentales de esta recuperación. Este punto de la reconstrucción de una nueva filosofia pública liberal desde la vuelta a una ética civica puritana aparece como el más controvertido de lo intentos NC. No se ve, tras sus previos análisis, cómo se pueden recuperar tales valores y cohonestarlos con el sistema económico. Para Walzer es un intento desmañado. $Y$ para Habermas y Dubiel un fallo de perspectiva global donde se confunden las causas con los efectos. Bell resume sus dudas respecto al éxito de la empresa y reitera, sin embargo, la validez del objetivo cuando dice: "es precisamente en el ámbito de la cultura donde el capitalismo es socavado y donde su "hegemonia" es prácticamente destruida. A este respecto, soy más pesimista que Habermas en lo concerniente a la capacidad a largo plazo de la sociedad capitalista para mantener su vitalidad como sistema moral y de recompensas para sus ciudadanos. Pero los fundamentos de la legitimidad pueden reposar en los valores del liberalismo político, si se le puede divorciar del hedonismo burgués .00

Una tercera línea de esta ofensiva cultural de los NC discurrre por el ataque, sin contemplaciones, a la nueva clase del conocimiento. Ya dijimo que los NC ven en ellos a los portadores sociales y a los corifeos de las actitudes y valores contrarios al capitalismo democrático. Todo el esfuerzo intelectual NC está dirigido a contrapesar el prodominio que esta nueva clase intelectual tiene, según su opinión, en las universidades, mass-media y esfera del arte. Desde este punto de vista se pudiera parafrasear a Nathan Glazer y hablar del NC como una "ofensiva defensiva" frente a la contracultura del liberalismo de izquierdas.

Finalmente hay que encuadrar en esta reconstrucción cultural de la filosoffa pública liberal NC los intentos dirigidos a exaltar las dimensiones morales del capitalismo. Estas atraviesan desde los beneficios que aporta el anonimato del mercado como instrumento de descarga política (Bell) hasta sus funciones equitativas mediante la distribución que efectuá a largo plazo (P. Berger); conjunta una gran modestia con sus pretenciones con el más eficaz rendimiento; proporciona una real co- 
munitariedad y ofrece sorprendentes afinidades con los puntos centrales de la doctrina cristiana (M. Novak). ${ }^{90}$ Pero de nuevo hay que senalar las dudas que se ciernen sobre estas pretensiones. Por esta razón, el proyecto NC se esfuerza por hacer creibles estas afirmaciones. Porque de lo que se trata es de lograr que los valores y las creencias de esta concepción NC del capitalismo democrático impregne el espacio público. El consenso social y la legitimación de lo que debe ser creible en la sociedad (estadounidense) es el objetivo al que apunta la recreación NC de la tradición liberal.

Antes de adentrarnos en el modo como atisban los NC la realización de este consenso, permitaseme recapitular los rasgos más marcados de la recreación NC de la tradición liberal. Será como insistir, una vez más, sobre las preeminencias más sobresalientes del paisaje NC.

EI NC o visión neoconservadora de la tradición liberal es una concepción de la sociedad (norteamericana) desde la afirmación de su pasado exitoso en la revolución capitalista puritana. Está estructurada por un capitalismo reticente a un excesivo intervencionismo estatal y a un Welfare State extenso, propugna las funciones regulares de la producción y distribución del mercado. Defiende una democracia representativa sospechosa de todo centralismo estatalizante y de la politización de las necesidades sociales, vehiculadas por las estructuras intermedias y las élites de los representantes. Aboga por una cultura con sabor trascendente (religión) y centrada en el individuo, pluralista y recuperadora de la ética puritana. Dirige sus criticas más acerbas a la nueva clase del conocimiento $y$, especialmente a los intelectuales del socialismo democrático. Su objetivo es lograr un nuevo consenso social que legitime esta concepción de la sociedad y asegure el predominio polftico de sus defensores.

¿Cómo piensan lograr los NC este consenso social en la situación actual norteamericana? Responder a esta cuestión nos introduce en algunos de los análisis y sugerencias NC sobre el momento actual y el futuro próximo. Equivalente a rastrerar con ellos sus potenciales aliados sociales o los legimadores sociales institucionalizados del proyecto NC.

\section{La búsqueda del nuevo consenso}

Las propuestas NC tienden a defender una concepción de la tradición liberal donde el individualismo se asiente en lo concerniente a los derechos individuales y la esfera de to económico y político, mientras su sensibilidad respecto a la salud y mantenimiento de la moral comunitaria se agudiza extraordinariamente por encima de las preferencias 
individuales." Esta actitud, que ellos mismo denominan "conservadores", hunde sus raices en la tradición religiosa americana. No tienen nada de extraño que algunos autores NC hayan avanzado por el camino de la religión y sus funciones como recreadora del humus moral o ética cívica para la allernativa NC.

\section{El problema del heredero de la tradiclón protestante}

La dificultad de la propuesta NC, como ya senalamos con sus críticos, es que quiere conjuntar dos aspectos contradictorios: simplificando hasta el estereotipo moral. Este equilibrio profundamente inestable, como han sefialado Bell y Lipset, se ve hoy amenazado no tanto por la ofensiva modemista que sienten agotada cuanto por "la nueva clase del conocimiento". Para salvar la incompatibilidad, si no contradicción de la propuesta NC, pretenden recuperar la tradición religiosa judeocristiana. Porque, como ha visto Bell, una ética civica que discipline el hedonismo de la cultura (modernista) dominante sólo parece encontrar sus raices en la religión. ${ }^{22}$

Pero cuando nos acercamos a la denominada tradición judeo-cristiana ${ }^{03}$ nos percatamos de su pluralismo y de que ella misma está atravesada por la misma división cultural-valorativa. Más aún, como evaluará Neuhaus, la fusión de alimentar ese humus moral -que Bell y los NC ven manar en sus últimos recovecos de la tradición y concepciones religiosas - la ejercitó tradicionalmente en la sociedad norteameriana la tradición central protestante. Pero esta tradición está en declive. Ha perdido justamente la capacidad de tonificar éticamente a la sociedad norteamericana." El problema ahora es quién será su heredero.

En la búsqueda del sucesor del protestantismo clásico (mainline Protestantism) que pueda proporcionar ese cimiento moral a la sociedad se avistan dos grupos: el fundamentalismo evangélico y el catolismo. ${ }^{.5}$ Estos son los llamados a proporcionar las bases legitimadoras de un sistema moral que ponga coto a la permisibilidad social y sean un impulso moral con fuerza motivacional y vinculatoria.

Neuhaus llegará a apostar claramente por el catolicismo como la tradición o iglesia cristiana donde se dan las condiciones objetivas para obtener un apoyo que combata "la crisis espiritual" de nuestro tiempo." Cuando observamos sus razones nos damos cuenta que se apunta claramente al catolicismo postconciliar restauracionista de Juan Pablo II y del cardenal Ratzinger como a la concepción con tal virtualidad. Esta tendencia posee la relación con el mundo que Neuhaus con P. Berger denominará paradójica porque engloba la actitud dialéctico-escatológica del "ya y todavia no", del contra el mundo en favor del mundo. Una 
actitud contra la modernidad que va más allá de la modernidad. La defensa de los valores tradicionales y la crítica de la idolatrla de lo politico (p. ej. contra el liberalismo religioso y la teología de la liberación) le parece a Neuhaus en ejercicio de esa actitud paradójica que hoy tendría la urgente tarea de dar sentido a la plaza pública vacia del hogar o sociedad liberal norteamericana: la producción del vínculo moral que una a los hombres de la plural sociedad americana. La religión (católica) es solicitada por el NC como la institución capaz de producir y expandir los contravalores que equilibren la situación de crisis del sistema capitalista democrátio. Pero ¿es realista esta expectativa?

\section{El problema del "hogar públlco"}

La cuestión fundamental radica, por tanto, en encontrar un impulso motivacional generador de espiritu civico, de voluntad y fortaleza para compartir y sacrificarse. EI NC anda a la búsqueda de solidaridad. Más allá de los problemas de la sobrecarga del Estado y de la alteración de la economla mundial está "cierto propósito moral, un telos que suministra la justificación moral de la sociedad". .7

Hay un convecimiento razonable entre los autores NC de que este lazo social que solidarice a los hombres unos con otros deriva de "las tradiciones valorativas y morales de la sociedad". No se pueden producir ni por intelectuales ni por expertos en "ingeniería social". La obra de justificación de los filósofos no es desechable, pero no engendra una nueva moral ni una nueva religión, dirá Bell teniendo en el trasfondo a W. Weber. La razón más profunda la encuentran nuestros autores en el carácter constitutivo que tiene la cultura para el hombre. $Y$ quien dice cultura afirma una respuesta coherente que reconcilie a "las modalidades esenciales que derivan de la finitud de la condición humana". Las preguntas siempre serán las mismas. Las respuestas variarán, pero no pueden desligarse de la religión. La adhesión a una ética solamente no resuelve el problema - a juicio de Bell- de la tensión entre lo particular y lo universal, o entre pasado, presente y futuro en que ha de vivir necesariamente el hombre. Para separar ámbitos y vivir en identidad parroquiales abiertas a un cosmopolitismo no vacio se requieren raices y se necesita el sentido de lo sagrado. ${ }^{\circ 0}$ De otro modo "quedamos en el caos del apetito y el egoísmo, y en la destrucción del círculo moral que cine a la humanidad". ${ }^{100}$

Este tratamiento religioso de la cuestión de la formación de una ética pública se liga en el pensamiento NC con el análisis de la situación actual: alejada del consenso protestante puritano que dominó durante 
mucho tiempo y que fue sustituido posteriormente por "un orden político único"101 Hoy este orden resquebrajado estructuralmente y valorativamente busca credibilidad, la ética católica restauracionista de nuestros dlas serla la encargada de recomponer los valores tradicional-puritanos donde de nuevo se conjunte un fuerte conservadurismo comunitarista en la moral personal con el individualismo en cuestiones económicas y politicas. Pero no es fácil que "el momento católico" se institucionalice tan homogéneamente como desearia Neuhaus. También la división recorre las iglesias. El catolicismo americano, además, ofrece un sorprendente progresismo en sus líderes (obispos) en las cuestiones económicas y de defensa. Sus posturas son más próximas a la nueva clase de la cultura adversaria que al NC. La reacción crítica de M. Novak asi to demuestra, ${ }^{102}$ como las miradas de Neuhaus hacia el Vaticano lo corroboran.

El recurso a las estructuras intermedias (familia, iglesia, asocianismo de vecinos...) tampoco puede representar en esta situación más que el intento que capitaliza las mediaciones moral-culturales más conserva. doras de la sociedad americana, para lograr credibilidad y apoyo para el sistema. Pero si la estrategia NC tiene claros signos de irrealismo, la conceptualización e impulso religioso de la ética civica indica un aspecto de la lógica NC en el tratamiento de la religión: su instrumentaliza. ción al servicio de su liberalismo económico y político. ${ }^{103}$

\section{La legitimación del capltallsmo democrátlco}

Abocamos asl al verdadero objetivo de la tarea NC por "infundir un nuevo vigor y autoconciencia intelectual en la ortodoxia burguesa americana" (I. Kristol): la legimación del sistema democrático con visión NC.

Este es el objetivo de la recreación liberal NC. Y ésta es "la cuestión más profunda y difícil" porque tiene que conjuntar "las motivaciones de los individuos y los fines morales de la nación", en expresión de D. Bell. ${ }^{104}$ Hay una crisis de motivación individual junto con una crisis de ética clvica cuando se mira hacia la legitimación. Estos son los dos componentes esenciales de la disyunción de los órdenes sociales que el NC llama crisis cultural o crisis espiritual. Llegados a esta altura se nos revela claramente to que se juega el NC en esta "guerra cultural": el ser o no ser de la sociedad capitalista democrática. $Y$ toda su recreación de la teorla liberal no es sino un gran esfuerzo por persuadir a los ciudadanos de la necesidad de colabororar al sostenimiento de esta noción NC de sociedad. La civitas invocada por el NC es "la voluntad espontánea para obedecer la ley" tal como la conciben ellos.

La estrategia legitimadora NC consta, como hemos visto, de una re- 
definición moral de los valores puritanos, en el trasfondo de la tradición judeo-cristiana y en un intento de dar sentido al hoy y al manana de América (=Norteamérica) desde un giro cultural conservador que pretende actualizar la genuina tradición americana.

El influjo polltico o reconocimiento que precisa toda legitimación no lo dejan estos autores a la pura fuerza de sus argumentos o convicciones, sino que tratan de expandirla mediante las fundaciones neoconservadoras y sus órganos de expresión y la actuación a través de los órganos de gobierno de la Administración republicana, concretamente y más intensamente en el segundo periodo del gobierno Reagan.

\section{Concluslones}

Después de este recorrido, predominantemente descriptivo, a través de la kulturkampf neoconservadora contra "la cultura adversaria de la nueva clase del conocimiento", estamos mejor preparados para comprender esta guerra cultural entre élites intelectuales como la manifestación de la profunda crisis cultural y la escisión de valores que recorre la sociedad americana y occidental. Asimismo entendemos el proyecto neoconservador por reinterpretar la tradición liberal como la pretensión de obtener un nuevo consenso social, es decir, una nueva legitimación para el capitalismo democrático en versión neoconservadora.

Quedan claros también en el trasfondo de la polémica neoconservadora las contraposiciones a cuya luz se define el proyecto NC.

1. La recuperación de la genuina tradición americana enraizada en la ilustración anglo-escocesa y la triunfante revolución norteamericana, frente a la ilustración continental, francesa, y su fracasada revolución.

2. La reconstrucción de la sociedad burguesa liberal actualmente en crisis, desde el intento de recuperar de nuevo la estabilidad entre el orden tecno-económico (inevitablemente dirigido por la racionalidad funcional y los intereses individuales) y un orden cultural que redescubra una ética civica puritana base de una nueva solidaridad.

En contraposición al énfasis cultural en la autorrealización y el hedonismo del esteticismo presentista de la nueva clase y la politización de sus demandas sociales que, sin embargo, no quieren perder el ritmo de creciento económico.

3) La propuesta NC en economla busca una alternativa a medio camino entre las doctrinas de Keynes y la socialdemocracia (hoy en crisis) y el neoliberalismo. Expresa un antiestatismo que mantiene un Welfare State moderado, pero tiende a descargar al Estado de la política social, entregando dichas cuestiones al mercado. 
Sus enemigos son tanto las políticas socialdemócratas que, según su visión, tienden al colectivismo, como el neoliberalismo que pretende desmantelar el Welfare State y entronizar la utopia del libre mercado inexistente.

4. La gobernalidad política se reforzaria reformando la administración para que fuera más eficaz (descarga burocrática, junto con la descarga real de tarea) impulsando una política representativa centrada en élites capaces y apoyada en las estructuras intermedias. Contra las tendencias de democracia directa y de politización creciente de más y más espacios que proponen, de hecho, socialistas democraticos y nuevos movimientos sociales.

5. El cambio cultural y de valores recibe una atención primordial. Aqul yace el problema principal. Se trata de crear un nuevo consenso alrededor de una ética cívica enraizada en la tradición y valores religiosos judeo-cristianos, donde se respete la primacia de autonomia individual, al mismo tiempo que se ponen limites al experimentalismo, se fomenta el autocontrol, la solidaridad con los demás y el sentido o vinculación trascendente.

Se sale asi al paso, dicen, del resentimiento que provoca en la mayoría de los americanos la imposición antidemocrática de unos valores arreligiosos y centrado en una ética yolsta de la autorrealización o las utoplas colectivistas.

6. La reformulación de una filosofía pública liberal es una cuestión esencial para obtener el consenso de la mayoria.Se trata de una concepción de la sociedad desde el individualismo liberal, la recuperación de una ética cívica de raices judeo-cristianas en el marco de una economla capitalista y un sistema político de entre los peligros del neoliberalismo y el socialismo. Una suerte de individualismo comunitario que entronca con la mejor tradición norteamericana.

7. El objetivo final es la legitimación del sistema capitalista democrático, carente de capacidad mitoutópica y necesitado de ser exaltado en sus impresionantes logros y virtualidades. Con ello se daiá un paso gigantesco en la recomposición y saneamiento de la cultura burguesa.

¿Lograrán estos intelectuales políticos que su reconstrucción de la filosoffa pública liberal triunfe?

Sin duda, el éxito de esta reconstrución está más allá de las contradicciones en las que incurren los NC. Dependerá en gran medida de una serie de circunstancias sociopolíticas externas a su teoria, aunque no desligadas de ella. 
Los recientes resultados de las elecciones norteamericanas, por ejemplo, junto con la fuerte presencia que posee este tipo de pensamiento en la Administración y en poderosas fundaciones (think tanks) para la creación y expansión de ideologia hace conjeturar un influjo persistente de este tipo de autores y de cuestiones en el ámbito del pensamiento sociopolítico y cultural americano.

\section{Notas}

1. Cfr. S. Martin Lipset, "Neoconservatismo: Myth and Reality", en Society (julio/agosto 1988), 29-37,29.

2. El término ha sido popularizado por M. Novak, The Spirit of Democratic Capitalism. American Enterprise Institute/Simon and Schuster, N. Y., 1982 trad. cast: El espiritu del capitalismo democrático (=ECD), Tres Tiempos, Buenos Aires, 1984; Ctr. P. Berger, The Caprialist Revolution, Basic Books, 1986, 65.

3. Cfr. las opiniones de J. Habermas, Die Neve Unübersichlichkeit, Suhrkamp, Frankfurt, 1986, en su confrontación con D. Bell, Las contradicciones culturales del capitalismo, Alianza, Madrid, 1977, y de H. Dubiel, Wasist Neokonservatismus?, Suhrkamp, Frankfurt, 1985, $11 \mathrm{s.}$

4. Cfr. I. Kristol, Reflections of a Neoconservative, Basic Books, N. Y., 1983, 35; D. Bell. Las contradicciones culturales, 80, 121 s. S. Martin Lipset, "Neoconservatism: Myth an Reality".

5. Cfr. R. Wuthnow, The restructuring of American Religion, Princeton, Un. Press, Priceton, 1988, 131 s., consolidada en la década 1973-83, 164 s., 170, 172; P. Steinfels, The Neoconservatives, Simon and Shuster, N. Y., 1980, 44 s.; idem, "Liberal Politics, conservative sentiment", en Dissent, vol. 35 (1988), 81-87, 84.

5. Cfr. A. de Tocqueville, Democracia en América, Alianza, Madrid, 1984, vol. 2, 128. También W. M. Sullivan, Reconstructing Public Philosophy, Calif. Univ. Press, Berkeley, Los Angeles, 1986 4. s. R. Bellah (ed.). Habits of the Heart, Harper and Row, N. Y., 1986, 20 s.

5b. Sullivan, Reconstructing Public Philosophy, $12 \mathrm{~s}$.

6. D. Bell, Las contradicciones culturales, 33, 64-73; cfr. También I. Kristol, Reflections, 175s.

7. La herencia puritana en la cultura y sociedad norteamericanas está ampliamente subrayada por todos los analistas sociales desde La Etica protestante del capitalismo, y el Espiritu del capitalismo, de M. Weber, hasta R. Bellah y otros, Habits of the Heart, 27 s. Valiosas también las sugerencias de J. Bensman/A. Vidich, American Society: The Welfare State and Beyond, Bergin and Garvey, North Hadley, MA, 1986; A. Vidich, "Religion, Economics, and Class in American Politics", en Politics, Culture and society. vol. 1, núm. 1, Otoño, 1987, 4-23.

8. D. Bell, Las contradicciones, 33.

9. Ibid., 33, 78.

10. Ibid., 33. 
11. Ibidem.

12. A. Vidich, "Religion, Economics, and Class in American Politics, 7.

13. Richard J. Neuhaus, The Naked Public Square. Religion and Democracy in America, Eerdmans, Grand Rapids, Michigan, 1986 (2 ${ }^{\circ}$ d.).

14. Cfr. J. Bensman/A. Vidich, American Society, 5 s., Berger/B. Berger/H. Kellner, Un mundo sin hogar, Sal Terrae, Santander, 1979, refllejan muy bien esta evolución; P. Wuthnow. The Restructuring of American Religion. $164 \mathrm{~s}$.

15. D. Bell, Las contradicciones culturales, 80.

16. Bbid., 84.

17. Cfr. Wuthnow, The Restructuring of the American Religion, 156.

18. Ibid., 156.

19. D. Bell, Las contradicciones culturales, 84.

20. Ibid., 84. El tema de "la nueva clase" es suficientemente importante entre los NC como para dedicarle casi todos ellos referencias extensas. La mejor compilación: B. Bruce-Briggs, The New class?, Transaction, N. Y., 1979.

21. Ibid., 89; Idem, "Modernism and Capitalism", en Partisan Review, 2 (1978), 206-22, 210, ahora como nuevo prólogo de la edición The Cultural contradiccions of Capitalism (1986).

22. Ibid., 31. Para una interpretación del individualismo burgués como un proceso de la modernización y no del capitalismo cfr. P. Berger, The Capitalism Revolution, Basic Books, N. Y., 1986, 96 s.

23. Ibid., 35, 260.

24. M. Novak, El esplritu del capitalismo democrático, Tres Tiempos, Buenos Aires, 1984, 46-47.

25. Ibid., Bell, Las contradicciones culturales, 27.

26. La expresion es de Bell, Las contradiciones culturales, 39, pero también se halla en I, Kristol, Reflections, 42; M. Novak, El espiritu del capitalismo democrático.

27. M. Novak, El esplritu del capitalismo democrático; P. Berger, The Capitalist Revolution, 196 s., que acentúa la capacidad "mitopoética" del socialismo y la paralela incapacidad del capitalismo (208). Los NC como Novak y Berger quisieran subsanar esta deficiencia mitica o autogeneradora de legitimación.

28. Cfr. Richard J. Neuhaus, The Naked Public Square; idem, "From Civil Religion to Public Phisolophy", en Leroy S. Rounes (ed.), Civil Religion and Political Theology, Univ. Notre Dame Press, Notre Dame, 1986, 98-111. 104.

29. Idem, "From Civil Religion", 105.

30. Hbid., IX.

31. Idem, The Catholic Moment.

32. Cfr. S. Martin Lipset, The First New Nation, Norton N. Y.Rondon (orig. 1963), 1979, Introducción (1979), XXXIII.

33. Hid., XXXIV.

34. Idem, "Neoconservatism: Myth and Reality", 29. 
35. Idem, The First New Nation, XL; D. Bell, Las contradicciones culturales, 261.

36. Esta afirmación, muy conocida dentro de la sociologla del conocimiento, es acentuada en sus consecuencias para la racionalidad y la justicia por A. Mclntyre. Whose Justice, Which Rationality?. Notre Dame Univ, Press, Notre Dame, 1988, 8 s.

37. Acerca de la presencia de los representates NC en fundaciones como American Interprise Institute, American Heritage, etc., en revistas como Public Interest. Commentary y puestos de la administración Reagan: J. Kirpatrik (representante en la ONU), N. Podhoretz y B. Wattenberg (en el aparato internacional de comunicaciones), M. Novak (embajador en la comisión de Derechos Humanos de las Naciones Unidas), W. Bennet (secretario de Educación), Ch. Finn. W. Kristol, G. Himmelfarb (mujer de I. Kristol) en el Consejo Nacional para dotación de humanidades, etc. cfr. S. Martin Lipset, "Neoconservatism: Myth and Reality", 34; p. Gottfried/T. Fleming, The Conservative Moment, Twayne, Boston, 1988, Cap. Cuarto, 59 s.; S. Blumenthal, The Rise of The Counterestablishment, Times Books (Randon House), N. Y., 1986, 122 s.; J. B. Judis, "Conservatives Stumble into the Future", Dissent, vol. 35 (1988).

38. Cfr. sobre todo I. Kristol, Reflections, 34, 35, 76; idem, "The spiritual Roots of Capitalism and Socialism", en M. Novak (ed.), Capitalism, AEL, Washington, 1979, 2 s.; M. Novak, El espiritu del Capitalism, democrático, 46.

39. Ibid., 84.

40. Cfr. P. Hollandes, "Alienation and The Adversary Culture", en Sociely (mayo-junio 1988), 40-48; (dem, "American Intellectuals: Producers and Consumers of Social Criticism", en A. Gragnon (ed.), Intellectual Liberal Democracies, Preager, N. Y., 1987, 67-86.

41. I. Kristol, Reflections, 143; M. Novak, El espiritu del capitalismo democrático, 14 s., 119, 122.

42. M. Novak, El esplritu del capitalismo democrático, 46.

43. I. Kristol, Reflections, XII, 76; M. Novak, El espiritu del capitalismo democrático, 122; D. Bell, Las contradicciones culturales, $237 \mathrm{~s}$.

44. P. Berger/T. Luckmann, La construcción social de la realidad, Amorrortu, Buenos Aires, 1974.

45. D. Bell, The Winding Passage, Basic Books, N. Y., 1980, XX-XXI; P. Berger, Ethic and New Class. Ethic and Public Policy Center, Washington, 1978.

46. S. Martin Lipset, "Neoconservatism: Myth and reality, 35 s.

47. D. Bell, Las contradicciones culturales, 188, 214.

48. Ibid., 36, 188, 223, 243.

49. Cir. I. Howe (ed.), Beyond the Welfare State, Schocken Books, N. Y., 1982, 7 s.; R. Heilbroner, The Nature and Logic of Capitalism, Norton, N. Y., con especial referencia a D. Bell.

50. D. Bell, Las contradicciones culturales, 169-170.

51. Ibid., 259; S. Martin Lipset, "Neoconservatism: Myth and Reality", 35-36. Idem (con I. Horowizz), Dialogues on American Politics, Oxford Univ. Press. N. Y., 1978, 45 s. 
52. Cfr. los artlculos de Ch. Murray, Losing Ground: American Social Policy, 1950-1980, Basic Books, 1984 (y el resumen de los crlticos y objeciones en Blumenthal, The Rise of the Counterestablishment, 295 s.); Nathan Glazer.

53. P. Berger.

54. D. Bell, Las contradicciones culturales, 170, 220, 224, 236.

55. Ibid., 1989; P. Berger (ed.), Modern Capitalism. Capitalism and Equality in America, Hamilton Press, Lanham/N. Y./London, 1987, 10.

56. Ibid., $224 \mathrm{~s}$. Para Bell "el núcleo del argumento liberal es que los hombres difieren en sus capacidades, necesidades, aptitudes y talentos. Asl, es menester distinguir entre tratar a la gente de manera igual y hacerlos iguales, 245. Críticamente R. Steinfels, The Neconservatives, Simon and Schuster, N. Y., 1979, 23 is.

57. Ibid., 244.

58. Ibid., 254 s. Para una valoración de conjunto de la atención del NC a Rawls cfr. P. Steinfels. The Neoconservatives, 235 s.

59. Ibid., 242 s.; I. Howe, Beyond The Wellare State, 6 s.

60. Ibid., 264 s. P. Steinfels, The Neoconservatives, 214 s.

61. Ibid., 194, 254; P. Berger, "La democracia en el mundo de hoy" (Commentary [1931]), Facetas, 1984, 2-6.

62. P. Berger, "La democracia en el mundo de hoy, 6. Bell, Las contradicciones culturales, 243, parece mostrarse mucho más escéptico que Berger y Neuhaus acerca de las posibilidades de estas estructuras o "grupos intermedios".

63. Ibid., 6; Idem, The Capitalist Revolution, 113.

64. Idem, The Capitalist Revolution, 81, 212.

65. Cfr. la critica de R. Heilbroner a D. Bell. Sobre las contradiociones culturales en este aspecto, cfr. The Nature and Logic of Capitalism.

66. P. Berger, The Capitalist Revolution, 7.

67. M. Novak, El espiritu del capitalismo.

68. P. Berger, The Capitalist Revolution, 6, $7 \mathrm{~s}$.

69. Ibid., 37.

70. Hid., 82.

71. Hid.

72. D. Bell, Las contradicciones culturales, 197; I. Kristol, Reflections, 202 s.

73. Bid., 201; Idem, "El mundo en el 2013", Facetas, núm, 81 (3/1988), 3-9, 6 (original, Daedalus, vol. 116, núm. 3 [1987]).

74. M. Novak, El espiritu del capitalismo democrático.

75. Ibid., 295.

76. P. Berger, The Capitalis Revolution, 62.

77. Ibid., 43, 46, 136.

78. Cfr. I. Kristol, Refletions, 139 s.; D. Bell, Las contradicciones culturales, 238; P. Berger, The Capitalist Revolution, 109.

79. P. Berger, The Capitalist Revolution, 109.

80. D. Bell, "El mundo en el 2013", 9.

81. P. Berger, The Capitalist Revolution, 68, tesis 15. 
82. D. Bell., Winding Passage, XV.

83. Idem, Las contradicciones culturales, 59-60.

84. Ibid., 62.

85. Cfr. Idem, "Modernism and Capitalism", Partisan Roview, 2 (1978), 206; I. Kristol, Reflections; Richard I. Neuhaus, The Naked Public Square, $X ; S$. M.; Lipset.

86. D. Bell, Las contradicciones culturales, 40.

87. Ibid., 153; idem, Modernism and Capitalism, 221.

88. Idem., Modernism and Capitalism, 222. Aunque hay un fuerte énfasis en "la necesidad funcional" de la religión. Bell se defiende de la acusación de funcionalizar la religión observando que más bien su concepción la ve como constitutiva de la cultura y de la finitud humana que conduce inexorablemente a poner límites a su poder (ibid., 221).

89. Idem, Las contradicciones culturales, 236.

90. Cfr. J. M. Mardones, "La asunción neo-conservadora de Weber, Sistema, 83 (1988), 25-41.

91. G. M. PlattR. H. Williams, "Religion, Ideology and Electoral Politics", Society, vol. 25, 5 (1988) 38-45, 39.

92. D. Bell, Las contradicciones culturales, 89; R. J. Neuhaus, The Naked Public Square, 21.

93. Denominación ésta que usa sólo un estereotipo o simbolo para muchos inaceptables y/o vacio. Tuvo su auge en el periodo posterior a laSegunda Guerra Mundial, pero ha sido criticada durante en las dos últimas décadas. Cfr. R. J. Neuhaus, The Naked Public Square; M. Silk, The Spiritual Politics, Simon and Schuster, N. Y./Londres, 1988, 40-53, 142 s; R. Wuthnow. The Restructuring of american Religion, Princeton Univ. Press, Princeton, N. J., 1988. 164 s.

94. Esta tesis de R. J. Neuhaus recorre sus dos obras. The Naked Public Square, IX, y The Catholic Moment, Harper and Row, San Francisco, 1987, 284, tesis 2.

95. Ibid., The Naked Public Square, IX; The Catholic Moment, 285, tesis 4.

96. Idem, The Catholic Moment, 24, 284 s. Precisamente porque entre los fundamentalistas evangélicos hay demasiadas afirmaciones (arbitrarias y autoritarias) contra el mundo y pocas para la empresa histórica (racional), R. J. Neuhaus rechaza el modo de relacionarse con el mundo del fundamentalismo; ctr. The Naked Public Square, 15.

97. D. Bell, Las contradicciones culturales, 88; R. J. Neuhaus, The Naked Public Square, 22.

98. Ibid., 88; Idem, Modernism and Capitalism, 221.

99. Ibid., 164.

100. Ibid., 164-165.

101./lbid., 88.

102. Cfr. M. NovakM. Joyce (ed.), Toward the Future: Catholic Social Thought and the U. S. Economy, Hamilton Press, Lanham/N. Y./Londres, 1986; P. Berger, "Can The Bishops Help The Poor?", Commentay, febrero 1985, 31-35; criticamente contra las posturas NC y en defensa de los obispos: P. 
Steinfels, The Bishops and their critics", Dissent, Primavera, 1985, 176182; W. Sullivan/R. Madsen, "The Bischops and their critics", Commonweal, 26 febrero 1988, 117-120.

Sobre la carrera armamentista y la postura de los obispos, cfr. M. Novak, "Arms and the Church", Commentary, marzo 1982, 37-41. Cfr. I. Kristol, Reflections, 326, y su desconsolada expresión ante la penetración de la cultura adversaria on las iglesias: $t \boldsymbol{t}$ is all very sad.

103. Crr. J. M. Mardones, "La asunción neo-conservadora de Weber", Sistema, 83 (1988).

104. D. Bell, Las contradicciones culturales, 88. 